
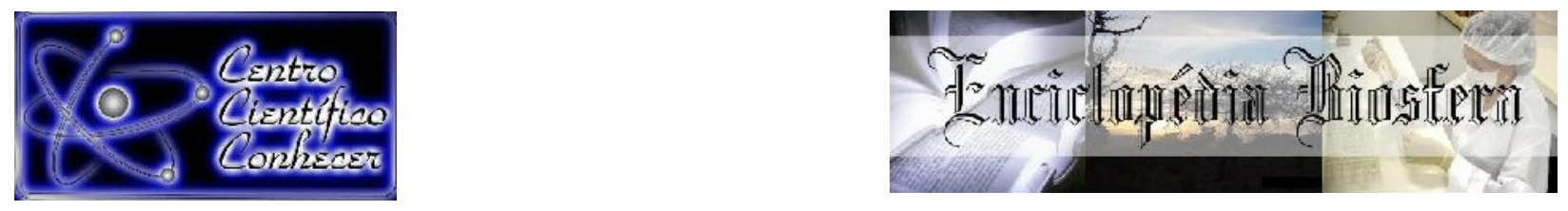

\title{
FORTALEZAS, FRAQUEZAS, OPORTUNIDADES E AMEAÇAS DAS ASSOCIAÇÕES FRENTE À CAPACIDADE ORGANIZATIVA E DESEMPENHO NA COMERCIALIZAÇÃO
}

\footnotetext{
Karla Karolline de Jesus Abrantes ${ }^{1}$; Patrícia Verônica Pinheiro Sales Lima ${ }^{2}$; Gema Galgani Silveira Leite Esmeraldo ${ }^{3}$; José Levi Furtado Sampaio ${ }^{4}$; Helena Selma Azevedo 5

${ }^{1}$ Mestre em Economia Rural/ Universidade Federal do Ceará (UFC), Fortaleza-CE, Brasil. E-mail: karlakarollineufc@yahoo.com.br

2 Professora Doutora no Programa de Pós-Graduação em Desenvolvimento e Meio Ambiente (PRODEMA)/UFC, Fortaleza-CE, Brasil.

${ }^{3}$ Professora Doutora no PRODEMA/UFC e no Programa de Pós-graduação em Avaliação de Políticas Públicas/UFC, Fortaleza-CE, Brasil.

${ }^{4}$ Professor Doutor no Departamento de Geografia/UFC, Fortaleza-CE, Brasil.

${ }^{5}$ Professora Doutora no Departamento de Estudos Interdisciplinares/UFC, FortalezaCE, Brasil.
}

\section{Recebido em: 15/02/2020 - Aprovado em: 15/03/2020 - Publicado em: 30/03/2020 DOI: 10.18677/EnciBio_2020A8}

\begin{abstract}
Este estudo teve por objetivo analisar a capacidade organizativa e o desempenho da comercialização de associações rurais. O artigo retrata um estudo de caso fundamentado na pesquisa-ação realizada em 15 entidades beneficiárias do Projeto de Desenvolvimento Rural Sustentável (PDRS)/Projeto São José III (PSJIII), da Secretaria de Desenvolvimento Agrário (SDA), do Governo do Estado do Ceará/Brasil, localizadas nos Territórios de Sobral, Extremo Oeste, Ibiapaba, Sertão Central e Centro Sul. Foi utilizada a matriz SWOT. O termo é um acrónimo de Forças (Strengths), Fraquezas (Weaknesses), Oportunidades (Opportunities) e Ameaças (Threats). Cada associação construiu a sua SWOT. Como principais resultados verificou-se que nos fatores analisados houve deficiência no desenvolvimento vivencial do grupo, precária condição de execução das tarefas grupais, gestão desmotivada e exclusão ou desvalorização de oportunidades de apoio de agentes externos para alcançar seu desenvolvimento socioeconômico. As associações que atuam com capacidade de articulação e de relacionamentos e que geram um ambiente de cooperação, participação, confiança e flexibilidade estão mais bem preparadas para assegurar um desempenho mais eficiente na comercialização.
\end{abstract}

PALAVRAS-CHAVE: Associações Rurais; Comercialização, Organização; 


\title{
STRENGTHS, WEAKNESSES, OPPORTUNITIES AND THREATS OF RURAL ASSOCIATIONS WITH REGARD ORGANIZATIONAL CAPACITY AND PERFORMANCE IN MARKETING
}

\begin{abstract}
This study aimed to analyze the organizational capacity and the performance of the marketing of rural associations. The article portrays a case study based on actionresearch carried out in fifteen beneficiary entities of the Sustainable Rural Development Project (PDRS) / São José III Project (PSJIII), of the Agrarian Development Secretariat (SDA), of the Government of the State of Ceará / Brazil, located in the Territories of Sobral, Extremo Oeste, Ibiapaba, Sertão Central and Centro Sul. The SWOT matrix was used. The term is an acronym for Strengths, Weaknesses, Opportunities and Threats. Each association built its SWOT. As main results it was verified that in the analyzed factors there was deficiency in the group's experiential development, precarious condition of performing group tasks, unmotivated management and exclusion or devaluation of opportunities for support from external agents to achieve their socioeconomic development. Associations that operate with a capacity for articulation and relationships and generate an environment of cooperation, participation, trust and flexibility are better prepared to ensure a more efficient performance in marketing.
\end{abstract}

KEYWORDS: Rural Associations; Organization; Marketing.

\section{INTRODUÇÃO}

Segundo o Serviço Nacional de Aprendizagem Rural (SENAR, 2011), o associativismo se constitui em alternativas necessárias que viabiliza as atividades econômicas, possibilitando aos/as trabalhadores/as e pequenos/as proprietários/as um caminho para participar do mercado em melhores condições de concorrência. De acordo com Cardoso (2014), por intermédio das associações, produtores/as se juntam para tentar um melhor desempenho econômico, no competitivo mercado. Quando unidos/as, facilita a aquisição de insumos e equipamentos agrícolas, reduz os custos e melhora os prazos e as condições de pagamento.

Entretanto, os estudos de Fagotti (2017) sobre associações de produtores rurais, revela a desorganização social como o maior problema enfrentado pelos/as agricultores/as familiares/as para o fortalecimento do associativismo, trazendo como consequências, dificuldades de comercialização conjunta da produção, aumento dos custos de produção e restrição no acesso ao crédito. Portanto, a organização de produtores/as rurais é importante como uma estratégia de comercialização, partindo da convicção que em uma unidade associativa/participativa os/as produtores/as têm melhores condições de defender seus interesses, de visualizar, analisar e de resolver seus problemas comuns, enfim, de se fortalecerem econômica e socialmente (CARDOSO, 2014).

O desafio consiste então, em participar e sustentar ações coletivas para continuar suas atividades para além do período de operação e alcance das necessidades, interesses e/ou problemas. Sem os processos organizacionais, ou seja, sem gestão eficiente para o funcionamento destas associações, se reproduzirão apenas como "agentes recreativos" (ROCHA, 2004). Deste modo, Denhardt (2012) afirma que é fundamental desenhar organizações com uma elevada capacidade de articulação e de relacionamentos, capazes de gerar um ambiente de cooperação, participação, confiança e flexibilidade. 
Desse modo, a cooperação é vista pelas políticas públicas como uma alternativa para a viabilização econômica desses/as agricultores/as. Assim, através das diversas formas de cooperação desde formas mais simples como a formação de associações até formas de cooperação mais complexas, como as cooperativas de produção agropecuária, as políticas públicas pretendem viabilizar economicamente os/as agricultores/as familiares. Com os programas do Governo, os/as associados/as poderão desfrutar de maior tranquilidade na hora de plantar e manter suas lavouras, como também aumentar os investimentos nos produtos e maquinários utilizados. Conseguir crédito a uma taxa de juros diferenciada é um enorme auxílio para aqueles que muito dependem de capital para manter seus negócios e os fazer prosperar (FAGOTTI, 2017).

Em face desse contexto, investigou-se a terceira edição do Projeto São José do Governo do Estado do Ceará (PSJIII), que beneficia associações e cooperativas rurais, no incremento das atividades econômicas nas áreas rurais e na ampliação do acesso à água potável e ao saneamento básico em todos os territórios rurais, com o claro compromisso de tornar mais favoráveis as condições de vida no sertão cearense (CASTRO; JAMEL, 2019).

Para a liberação desse incremento dos projetos produtivos, no âmbito de cadeias produtivas promissoras, o PSJIII achou necessário capacitar às entidades beneficiárias em gestão administrativa e financeira, a fim de evitar problemas no planejamento, desenvolvimento e sustentabilidade das atividades integradas a serem articuladas, numa perspectiva de fortalecimento dessas cadeias, desde os insumos básicos até o produto final, incluindo a inserção sustentável nos respectivos mercados (CEARÁ, 2019).

Atendendo as novas demandas do PSJIII, o Governo do Estado, por meio da Secretaria de Desenvolvimento Agrário (SDA) e do Instituto Agropolos do Ceará (Agropolos), firmou um convênio com o Instituto Nacional de Desenvolvimento Social e Qualificação Profissional (IDESQ), para preparar as entidades rurais a desenvolverem práticas de gestão, bem como, abordar ações construtivistas e participativas para sanar os desafios apontados (AGROPOLOS, 2017).

Nesse convênio, aceitou-se o convite do IDESQ a se fazer parte da equipe de instrutores/as nas ações solicitadas pelo Agropolos. A experiência, de quase 12 meses, dialogou com a construção desse artigo, pois paralelo às intervenções no trabalho de campo investigou-se as limitações e os entraves dos/as agricultores/as familiares, mesmo acompanhados/as de assistência técnica, em produzir e comercializar a produção, quando se tem uma organização fragilizada.

Durante as ações, em 15 associações rurais, surgiu como pergunta de partida: existe ou não relação entre a capacidade organizativa e o desempenho na comercialização dos/as agricultores/as familiares? Para que fosse possível equacionar a questão, o estudo teve como objetivo geral analisar a capacidade organizativa e o desempenho da comercialização das associações rurais.

\section{Recorte temporal e espacial}

\section{MATERIAL E MÉTODOS}

A pesquisa teve como unidade de observação associações de produtores/as rurais que estivessem recebendo Assistência Técnica e Extensão Rural (ATER) do Instituto Agropolos e também ligadas ao Projeto de Desenvolvimento Rural Sustentável (PDRS)/Projeto São José III (PSJIII). Essas associações estariam recebendo capacitações a fim de melhorar os resultados organizacionais, de gestão 
e técnicas produtivas.

Uma das capacitações foi o Curso de Gestão Administrativa e Financeira, sendo o IDESQ a instituição credenciada responsável por executar. Participando da equipe de profissionais, o método de seleção das organizações foi realizado aleatoriamente (sem critérios), para cada consultor/a atuar. Das 82 organizações beneficiadas com o Projeto denominado "Trilhas para a transformação: capacitações para povos e comunidades tradicionais", a pesquisa atuou em 15 associações.

Os cursos foram executados, bem como a coleta de dados da pesquisa, durante o período de setembro de 2017 a junho de 2018, totalizando uma carga horária de 252 horas. Durante esses 10 meses, os cursos e a pesquisa de campo foram realizados em três etapas e distribuídos em três módulos: 1) Gestão Administrativa; 2) Gestão Financeira; 3) Gestão Administrativa e Financeira.

Esse artigo utilizou o recorte temporal e espacial do primeiro módulo, que foi executado in loco, em cada comunidade ou assentamento rural vinculado à associação, identificando a realidade do local e da associação, o motivo da criação da organização e o cenário em que a associação se encontrava. Foi a fase mais longa da pesquisa, pois se passava dois dias em atividade com cada uma das 15 associações. Essa permanência em campo de aproximadamente três meses, permitiu abrir espaço para uma relação de maior confiança entre pesquisadores/aspesquisados/as, fundamental na abordagem de temas que envolvem relações sociais.

Assim, durante os meses de outubro a dezembro de 2017 foram visitadas as regiões Oeste e Centro-Sul do Ceará, nos municípios de Acaraú, Camocim, Granja, Viçosa do Ceará, Tianguá, São Benedito, Meruoca, Sobral, Groaíras, Mombaça, Piquet Carneiro, Irapuan Pinheiro e Iguatu. As áreas percorridas durante a pesquisa pertencem a cinco territórios: quatro associações estão no Território Litoral Extremo Oeste, três no Território de Sobral, quatro na Serra da lbiapaba, três no Sertão Central e uma no Centro Sul.

No Quadro 1 abaixo é possível visualizar a distribuição das organizações associativas por território, suas denominações abreviadas, seguidas de um código ${ }^{1}$, seus respectivos municípios e suas atividades econômicas principais.

QUADRO 1 - Recorte Espacial das Associações Rurais Pesquisadas por Território.

\begin{tabular}{|c|c|c|c|c|c|}
\hline № & TERRITÓRIO & MUNICÍPIO & ENTIDADE & CÓDIGO & ATIVIDADE \\
\hline \multirow{4}{*}{1} & \multirow{4}{*}{$\begin{array}{l}\text { SERRA DA } \\
\text { IBIAPABA }\end{array}$} & \multirow{2}{*}{ VIÇOSA } & $\mathrm{ACU}$ & A & $\begin{array}{c}\text { Agricultura Familiar Com Aporte Tecnológico - } \\
\text { FRUTICULTURA }\end{array}$ \\
\hline & & & ACGFD & B & $\begin{array}{c}\text { Agricultura Familiar Com Aporte Tecnológico - } \\
\text { FRUTICULTURA }\end{array}$ \\
\hline & & TIANGUA & ACR & C & $\begin{array}{c}\text { Agricultura Familiar Com Aporte Tecnológico - } \\
\text { OLEIRICULTURA }\end{array}$ \\
\hline & & $\begin{array}{c}\text { SÃO } \\
\text { BENEDITO }\end{array}$ & AMSI & D & $\begin{array}{c}\text { Agricultura Familiar Com Aporte Tecnológico - } \\
\text { PANIFICAÇÃO/POLPAS }\end{array}$ \\
\hline & & 3 & 4 & & \\
\hline \multirow[t]{2}{*}{2} & \multirow{2}{*}{$\begin{array}{l}\text { LIRORAL EXTREMO } \\
\text { OESTE }\end{array}$} & \multirow{2}{*}{ CAMOCIM } & ACMT & $E$ & APICULTURA \\
\hline & & & ACC & $\mathrm{F}$ & APICULTURA \\
\hline
\end{tabular}

\footnotetext{
${ }^{1}$ Todos os nomes das associações estão representados por letras, como forma de assegurar o anonimato delas e não expô-las a qualquer tipo de constrangimento, sem, no entanto, deixar de servir de um exemplo real para o aprendizado.
} 


\begin{tabular}{|c|c|c|c|c|c|}
\hline & & ACARAÚ & ACCAV & $\mathrm{G}$ & $\begin{array}{l}\text { Agricultura Familiar Com Aporte Tecnológico - } \\
\text { COCOICULTURA }\end{array}$ \\
\hline & & GRANJA & ACANJ & $\mathrm{H}$ & $\begin{array}{c}\text { Agricultura Familiar Com Aporte Tecnológico - } \\
\text { MANDIOCULTURA/CAJUCULTURA }\end{array}$ \\
\hline & & 3 & 4 & & \\
\hline \multirow{4}{*}{3} & \multirow{3}{*}{ SERTÃO CENTRAL } & $\begin{array}{l}\text { IRAPUAN } \\
\text { PINHEIRO }\end{array}$ & ACPASR & 1 & APICULTURA \\
\hline & & MOMBAÇA & AAMM & $J$ & APICULTURA \\
\hline & & $\begin{array}{c}\text { PIQUET } \\
\text { CARNEIRO }\end{array}$ & AAPC & $\mathrm{K}$ & APICULTURA \\
\hline & & 3 & 3 & & \\
\hline \multirow[t]{2}{*}{4} & $\begin{array}{c}\text { CENTRO SUL E } \\
\text { VALE DO SALGADO }\end{array}$ & IGUATU & APRAS & $\mathrm{L}$ & OVINOCAPRINOCULTURA \\
\hline & & 1 & 1 & & \\
\hline \multirow{3}{*}{5} & \multirow{3}{*}{$\begin{array}{l}\text { SERTÃO DE } \\
\text { SOBRAL }\end{array}$} & MERUOCA & ACSE & M & $\begin{array}{c}\text { Agricultura Familiar Com Aporte Tecnológico - } \\
\text { FRUTICULTURA }\end{array}$ \\
\hline & & SOBRAL & APABJ VI & $\mathrm{N}$ & $\begin{array}{l}\text { Agricultura Familiar Com Aporte Tecnológico - } \\
\text { MANDIOCULTURA }\end{array}$ \\
\hline & & GROAÍRAS & ACJ & $\mathrm{O}$ & $\begin{array}{l}\text { Agricultura Familiar Com Aporte Tecnológico - } \\
\text { QUINTAIS PRODUTIVOS E AVICULTURA }\end{array}$ \\
\hline
\end{tabular}

Fonte: Dados da pesquisa (2019).

\section{Estudo de caso como estratégia de pesquisa}

Como estratégia de pesquisa, utilizou-se o estudo de caso, para contribuir com o conhecimento que se têm dos fenômenos individuais, organizacionais, sociais, políticos e de grupo, além de outros fenômenos relacionados. A modalidade permitiu uma investigação que preserva as características holísticas e significativas dos acontecimentos da vida real, permitindo uma apreensão bastante minuciosa das relações sociais (YIN, 2015).

Adequada aos propósitos do estudo de caso, adotou-se como técnica para coleta de dados e evidências, a pesquisa de ação participativa (PAR, sigla em inglês), na qual as pessoas "de dentro" do contexto social participam da pesquisa junto com o/a(s) pesquisador/a(s) "de fora", para que, de forma colaborativa, investiguem um problema da realidade em que estão inseridas e criem meios de mudança social (NOFFKE; SOMEKH, 2015).

A concepção da PAR, vista por Noffke e Somekh (2015) como uma estrutura de interação entre os agentes envolvidos, foi conduzida a partir de intervenções no âmbito das organizações associativas, com procedimentos de diagnóstico para identificar o cenário da associação e consultoria com efeito de aprendizagem, concebido como conscientização para sanar uma situação complexa e encaminhar possíveis soluções e ações, especialmente nas situações insatisfatórias ou de crise.

\section{Matriz FOFA ou SWOT como método de pesquisa para obtenção dos dados}

$\mathrm{Na}$ coleta das informações para entender o nível organizacional das associações e para relacionar isto às questões de acesso à comercialização, fez-se uma análise de cenário (ou análise de ambiente) em que a associação se encontrava, adotando a ferramenta analítica proposta por Hindle e Lawrence (1994) e Tarapanoff (2001), a matriz FOFA ou SWOT.

O termo SWOT é uma sigla oriunda do idioma inglês, e é um acrónimo de quatro fatores: Forças (Strengths), Fraquezas (Weaknesses), Oportunidades 
(Opportunities) e Ameaças (Threats). Portanto, em português, chama-se FOFA. A matriz FOFA é um sistema simples, de baixo custo, usado como catalisador para estruturar a gestão e a geração das estratégias de uma organização ou empresa, possibilitando o alinhamento da missão e visão da entidade às oportunidades oferecidas pelo ambiente externo (HINDLE; LAWRENCE, 1994).

Cada associação construiu a sua matriz. Para uma melhor análise, reuniramse todas as indicações de forças, oportunidades, fraquezas e ameaças apontadas pelos/as próprios/as associados/as, ordenou-se a frequência dessas indicações em cada um dos quatros fatores $\left(n_{i}\right)$ e construiu-se a Matriz FOFA com os dados primários totais.

\section{RESULTADOS E DISCUSSÃO}

$\mathrm{Na}$ construção da Matriz FOFA foram reunidas 39 indicações distribuídas no fator Força; 50 apontadas como Fraqueza; 40 resgatadas como Oportunidade; e 42 alertadas como Ameaça. Com o grande número de indicações para analisar elencou-se as seis mais citadas em cada fator e redirecionaram-se as informações. Por fim, tem-se a Matriz FOFA no Quadro 2.

QUADRO 2 - Indicações de forças, oportunidades, fraquezas e ameaças nas associações rurais e suas respectivas frequências - Matriz FOFA

\begin{tabular}{|c|c|c|c|}
\hline ternos & & & \\
\hline $\begin{array}{l}1.1 \text { Forças } \\
\text { União } \\
\text { ex } \cdot \text { do gruno nas vendas do mel }\end{array}$ & $n_{i}$ & 1.2 Fraquezas & $n_{i}$ \\
\hline $\begin{array}{l}\text { União (ex.: do grupo nas vendas do mel, } \\
\text { na colheita, nas moagens de cana) }\end{array}$ & 12 & $\begin{array}{l}\text { Baixa participaçăo nas reuniōes, nos } \\
\text { mutirões/coletivos }\end{array}$ & 8 \\
\hline Organização & 8 & $\begin{array}{l}\text { Falta de transporte para venda e colheita } \\
\text { dos produtos }\end{array}$ & 6 \\
\hline $\begin{array}{l}\text { Contribuição ativa, Doação, Apoio } \\
\text { financeiro, arrecadação das mensalidades } \\
\text { dos sócios }\end{array}$ & 7 & Desunião & 5 \\
\hline $\begin{array}{l}\text { Mão de obra, Mutirão/ trabalho coletivo } \\
\text { (ex.: nas moagens) }\end{array}$ & 6 & Poucos recursos financeiros & 5 \\
\hline Terra (conquista, posse) & 6 & Desorganização & 5 \\
\hline $\begin{array}{l}\text { Competência, conhecimentos, informação, } \\
\text { qualificação, experiência dos apicultores }\end{array}$ & 5 & Desmotivação, desânimo & 4 \\
\hline
\end{tabular}

2. Fatores externos

\begin{tabular}{lc|lr} 
2.1 Oportunidades & $n_{i}$ & 2.2 Ameaças & $n_{i}$ \\
\hline Cursos e capacitações em geral & 15 & Invernos irregulares & 12 \\
\hline Recursos Hídricos & 15 & $\begin{array}{l}\text { Pragas e doenças nas unidades de } \\
\text { produção }\end{array}$ & 10 \\
\hline Assistência técnica & 12 & $\begin{array}{l}\text { Ação dos intermediários na venda dos } \\
\text { produtos }\end{array}$ & 9 \\
\hline Políticas Públicas e Projetos & 12 & Queimadas e desmatamento & 7 \\
\hline Distribuição elétrica (energia) & 10 & Falta água potável para beber & 6 \\
\hline Parcerias e apoio & 9 & Assistência técnica (ausência) & 5 \\
\hline
\end{tabular}

Fonte: Resultados da pesquisa (2019).

Esses quatro fatores são baseados em conceitos ambivalentes: "interno $x$ externo" e "positivo x negativo". As forças e fraquezas são determinadas a fatores internos. Já as oportunidades e ameaças estão relacionadas a fatores externos. Entretanto, Tarapanoff (2001) adverte que os conceitos da FOFA não devem ser ENCICLOPÉDIA BIOSFERA, Centro Científico Conhecer - Jandaia-GO, v.17 n.31; p. 922020 
considerados em termos absolutos (tudo depende do ambiente): uma oportunidade também pode ser uma ameaça; e um ponto forte pode ser um ponto fraco em outro contexto.

Conforme Hindle e Lawrence (1994), o ambiente interno pode ser controlado pelo indivíduo, uma vez que é resultado das estratégias de atuação definidas por ele mesmo. Desta forma, durante a análise, quando for percebido um ponto forte, ele deve ser ressaltado ao máximo; e quando for percebido um ponto fraco, o indivíduo deve agir para controlá-lo ou, pelo menos, minimizar seu efeito. Já o ambiente externo está totalmente fora do controle. Mas, apesar de não poder controlá-lo, o indivíduo deve conhecê-lo e monitorá-lo com frequência, de forma a aproveitar as oportunidades e evitar as ameaças. Evitar ameaças nem sempre é possível, no entanto, pode-se fazer um planejamento para enfrentá-las, minimizando seus efeitos.

Taparanoff (2001) esquematiza a análise de Hindle e Lawrence (1994) em quatro tarefas principais: i) Tarefa 1: Avaliação de Forças e Fraquezas; ii) Tarefa 2: Equiparação de Forças e Oportunidades; iii) Tarefa 3: Conversão de Fraquezas em Forças e de Ameaças em Oportunidades e iv) Tarefa 4: Desqualificação das Fraquezas e Ameaças que não podem ser transformadas. Na explicação da autora, a Tarefa 1 tem o exercício de autoavaliação, olhar de forma intrínseca para dentro da organização e refletir sobre o que a impede de ser sustentável.

$\mathrm{Na}$ Tarefa 2 a análise da matriz começa a cruzar suas linhas e colunas, pois relaciona fatores externos com internos. As células da matriz podem ser entendidas como combinações de fatores: i) combinação $A=$ pontos fortes e oportunidades, ii) combinação $B=$ pontos fortes e ameaças; iii) combinação $C=$ pontos fracos $e$ oportunidades e iv) combinação $D=$ pontos fracos e ameaças. Na combinação $A$, deve-se verificar sua aplicação e sustentabilidade ao longo do planejamento; a B contribui no controle de ameaças, devem ser operacionais; já nas combinações $\mathrm{C}$ e $D$, os fatos devem-se ser corrigidos ou eliminados. Devem-se identificar passivos importantes, ocorridos quando uma fraqueza reforça uma ameaça. Sua transformação é prioritária (TARAPANOFF, 2001).

Segundo Tarapanoff (2001), a Tarefa 3 tem o objetivo de minimizar, evitar ou eliminar os fatores negativos, sejam eles do ambiente interno ou externo. Ou seja, converter as fraquezas em fortalezas, e as ameaças em oportunidades, se os recursos corretos estiverem disponíveis. Por fim, Tarapanoff (2001) revela que na Tarefa 4 as principais fraquezas que não são transformadas em forças tornam-se limitações. Essas limitações se tornarão óbvias e significativas para os agentes envolvidos na organização. Ocorrem mais frequentemente quando a fraqueza ou ameaça coincide com uma das oportunidades. É preciso definir o que será feito para manter os pontos fortes, melhorar os pontos fracos, aproveitar as oportunidades e minimizar ou evitar os riscos das ameaças apontadas.

Orientando-se pelos esquemas de Hindle e Lawrence (1994) e Taparanoff (2001) analisaram-se, aleatoriamente, as internalidades, as externalidades e as combinações entre as indicações da Matriz, de acordo com o cenário das organizações associativas e a busca conjunta por soluções específicas e viáveis para a transformação da situação.

A indicação união se apresenta no primeiro lugar do ranking do fator força, 12 associações elegeram como um ponto positivo dentro da organização. Nas falas dos/as associados/as da Associação $\mathrm{N}$ é possível compreender o grau de significância desse valor, ao pronunciarem que na "(...) associação tem que ser todo 
mundo reunido, trabalhando junto, ajudando uns aos outros (...), se não tiver união nada vai para frente" (informação verbal) ${ }^{2}$, ou seja, sem união, na busca de um objetivo comum, não há desenvolvimento. Em acréscimo, a Associação $D$ complementa metaforicamente ao dizer que "uma equipe unida sabe que só se alcança qualquer destino quando todas remam na mesma direção" (informação verbal) ${ }^{3}$.

Essa união dos/as pequenos/as produtores/as em associações torna possível a aquisição conjunta de insumos e equipamentos com menores preços e melhores prazos de pagamento, como também o uso coletivo de tratores, colheitadeiras, melgueiras, etc. Tais recursos, quando divididos entre vários/as associados/as, tornam-se acessíveis e o/a produtor/a certamente minimiza seus custos, pois reúnem esforços em benefício comum, bem como o compartilhamento de despesas com manutenção de equipamentos e matéria prima. Ressalta-se que além da economia de valores econômicos, a união colabora também com a força de trabalho, pois na maioria das associações reúnem a mão de obra no roçado, nas colheitas e extrações de mel, nas moagens de cana, nas extrações do carnaubal, nas colheitas do coco, nas "farinhadas" (fabricação de farinha e goma de mandioca), nas fabricações de bolos e biscoitos, e nas vendas, por exemplo.

Analisando também a força contrária, que aparece na FOFA como a terceira indicação negativa, dentro do cenário interno da associação, a desunião, se não erradicada, vem a atrapalhar o desenvolvimento da comunidade. Torna-se então, estrategicamente fundamental a organização de agricultores/as em associações para fins de planejamento de atividades que oportunizem o acesso a canais de comercialização ou mesmo algum tipo de especialização de produção, no intuito de aumentar a pauta de produtos e evitar possíveis problemas relacionados à emancipação socioeconômica dos/as agricultores/as familiares, entre outros.

No Quadro 3, que não só pôde observar o antagonismo união versus desunião, mas também, organização versus desorganização, avalia-se que é necessário desenvolver a Tarefa 3 de Tarapanoff (2001), que é converter as fraquezas em fortalezas, assim evitará que os fatores internos negativos não se tornem uma limitação na capacidade organizativa e consequentemente no desempenho da comercialização.

QUADRO 3 - Avaliação de forças e fraquezas a partir do antagonismo

\begin{tabular}{|c|c|c|c|}
\hline 1.1 Forças & $n_{i}$ & 1.2 Fraquezas & $n_{i}$ \\
\hline $\begin{array}{l}\text { União (ex.: do grupo nas vendas do mel, } \\
\text { na colheita, nas moagens de cana) }\end{array}$ & 12 & Desunião & 5 \\
\hline Organização & 8 & Desorganização & 5 \\
\hline
\end{tabular}

Fagotti (2017) apontou no seu estudo que a desorganização é o maior problema enfrentado pela associação no momento da comercialização, e que a organização é uma ferramenta estratégica para acessar os mercados, pois parte-se

\footnotetext{
2 Informação fornecida em outubro de 2017, durante o Módulo I, na Associação N, Sobral-CE.

3 Informação fornecida em novembro de 2017, durante o Módulo I, na Associação D, São BeneditoCE.
} 
do entendimento que a associação organizada terá melhores condições de buscar e alcançar seus interesses comuns.

Uma das três maiores ameaças para as associações é a ação dos intermediários na venda dos produtos. Essa figura, denominada informalmente de "atravessador", passa a existir quando a distribuição e a circulação da produção deixam de ser feita diretamente por quem produz, tornando-se dependente de um intermediário, "que possui interesses, custos e, portanto, lança mão de mecanismos de controle e regulação para manter o poder, tais como certificados de produtos, preços diferenciados segundo a regularidade da oferta, entre outros" (SCHNEIDER, 2016, p.123).

Belik e Cunha (2015) classificam essa intermediação em duas categorias: funcional ou especulativa. $O$ atravessador especulativo se apropria do lucro dos/as produtores/as, sem agregar valores pós-colheita, como classificação e melhoria do acondicionamento. Já o que atua de forma funcional, geralmente, mantém o vínculo rural e local, reunindo a produção de toda a comunidade. Os autores defendem que esse atravessador funcional, que também é produtor rural, acaba mudando o campo de atuação principal da produção para a atividade comercial.

Trata-se de um paradoxo já que para algumas organizações, o atravessador é um "mal necessário", pois a comunidade ainda não está preparada para se desvincular dessa figura. Como é o caso da Associação $\mathrm{C}$, em que o intermediário comercial é próprio da comunidade, inclusive vice-presidente da associação. Portanto, atua de forma funcional, reunindo a produção de todos/as produtores/as e levando para a Central de Abastecimento Atacadista (CEASA) de Tianguá e para a Feira Municipal de Viçosa, seguindo sempre a base de dados, vinculada à Companhia Nacional de Abastecimento (CONAB), e arrecadando sua porcentagem sobre os produtos.

Dessa forma, combinando esse fator externo com os internos da matriz FOFA, têm-se algumas forças relevantes que podem contribuir no controle dessa ameaça (não tanto agressiva) do atravessador, como a mão de obra familiar e o trabalho coletivo, aparados de colaboração, participação, apoio e solidariedade. Ou seja, a ameaça de mercado pode ser contingenciada por meio da força e cooperação do grupo. Essa combinação ou cruzamento B de Tarapanoff (2001), pode ser visualizada abaixo, no Quadro 4.

QUADRO 4 - Combinações de fatores que influenciam a capacidade organizativa e o desempenho da comercialização nas associações rurais.

\begin{tabular}{|c|c|c|}
\hline $\begin{array}{ll}\text { Fator interno } & \text { Fator externo } \\
\end{array}$ & OPORTUNIDADE & $\overline{\text { AMEAÇA }}$ \\
\hline \multicolumn{3}{|c|}{ COMBINAÇÃO A } \\
\hline $\begin{array}{l}\text { PONTOS FORTES: Competência, } \\
\text { qualificação, conhecimentos, } \\
\text { informação, experiência dos } \\
\text { apicultores }\end{array}$ & $\begin{array}{l}\text { (A) Cursos/capacitações em } \\
\text { geral; assistência técnica; } \\
\text { políticas públicas e projetos; } \\
\text { parcerias e apoios }\end{array}$ & (B) \\
\hline PONTO FRACO & (C) & (D) \\
\hline \multicolumn{3}{|c|}{ COMBINAČÃO B } \\
\hline $\begin{array}{l}\text { PONTOS FORTES: Mão de obra, } \\
\text { Mutirão/ trabalho coletivo }\end{array}$ & (A) & $\begin{array}{l}\text { (B) Ação dos intermediários } \\
\text { na venda dos produtos }\end{array}$ \\
\hline PONTO FRACO & (C) & (D) \\
\hline \multicolumn{3}{|c|}{ COMBINAÇẤO C } \\
\hline PONTO FORTE & (A) & (B) \\
\hline
\end{tabular}




\begin{tabular}{|c|c|c|}
\hline $\begin{array}{llr}\text { PONTO } & \text { FRACO: } & \text { Baixa } \\
\text { participação nas reuniões, nos } \\
\text { mutirões/coletivos }\end{array}$ & $\begin{array}{c}\text { (C) Políticas Públicas e } \\
\text { Projetos }\end{array}$ & (D) \\
\hline \multicolumn{3}{|c|}{ COMBINAÇÃO D } \\
\hline PONTO FORTE & (A) & (B) \\
\hline $\begin{array}{l}\text { PONTO FRACO: Falta de } \\
\text { transporte para venda e colheita } \\
\text { dos produtos }\end{array}$ & (C) & $\begin{array}{c}\text { (D) Ação dos intermediários } \\
\text { na venda dos produtos }\end{array}$ \\
\hline
\end{tabular}

Fonte: Resultados da pesquisa (2019).

A combinação $D$ revela a existência de fraquezas que podem potencializar ainda mais a ameaça, como é o caso da ausência de transporte para coletar e vender os produtos, considerado como um dos fatores internos negativos mais relevantes para a distribuição na comercialização. Nessa circunstância, em que a combinação se encontra no ponto $D$, os planos de ação devem ser de contingência e emergenciais.

Assim, para corrigir essa fraqueza e eliminar essa ameaça, as associações trouxeram como plano de ação a seguinte solução: elaborar projetos, por meio das instituições parceiras, com o objetivo de contemplar a associação com um veículo adequado para colher e transportar a produção, com compartimentos isolados que garantam, durante 0 transporte, o controle da temperatura e a ausência de contaminantes externos, componentes importantes para manter a qualidade sanitária dos produtos. Na sistematização, definiram estratégias como: uma comissão responsável para a confecção do projeto, os prazos pela busca e os custos. Outra solução apresentada pelas associações, para reverter essa dificuldade em escoar a produção, devido à falta de um transporte, foi o acúmulo de dinheiro arrecadado em bingos e rifas. Apesar de válida, pois a associação tem potencial e capacidade para resolver seus problemas e necessidades, é uma proposta atemporal, pois para atingir o valor final requer um período de tempo indeterminado.

Cruzando mais uma vez os fatores internos com os externos, dessa vez ambos positivos, observou-se que algumas forças das associações podem potencializar oportunidade de mercado. Exemplificando, tem-se como indicação, no fator força, o alto nível de competência e qualificação dos/as associados/as (ou capacidades, de acordo com o PSJIII), dialogando com as indicações do fator oportunidade: cursos/capacitações em geral; assistência técnica; políticas públicas e projetos; parcerias e apoios institucionais. Caso da combinação $A$, no Quadro 4.

$\mathrm{Na}$ combinação A, Tarapanoff (2001) indica verificar a aplicação e sustentabilidade ao longo do planejamento. Assim, ressalta que todas as associações consideraram todo tipo de curso e/ou capacitação uma oportunidade de desenvolvimento. Essa indicação, apresentada na FOFA com frequência total, juntamente com as demais indicações positivas do ambiente externo, podem capacitar mais ainda os/as produtores/as associados/as para alcançar maior produtividade, maior produção e melhores resultados econômicos em função do aumento do volume de produtos comercializados, levando ao aumento da receita. Quanto ao escoamento, contariam também com esses fatores externos para assinalar os possíveis canais de comercialização.

Dentre as indicações de oportunidade, levantadas acima na combinação $A$, destaca-se que a indicação assistência técnica não só foi apresentada como fator externo positivo, como também, foi apontada como um fator externo negativo (ver 
Quadro 2). Para as associações, é uma ameaça a falta de continuidade no serviço de ATER, que é um direito dos povos do semiárido. Numa descontinuidade do contrato, a comunidade deve estar unida e organizada para reivindicar um serviço de qualidade e continuado; ou mesmo, para se preparar a trabalhar sem a dependência externa, já que é inconstante. Contudo, é necessário traçar planos de ação para aproveitar ao máximo os fatores positivos que surgirem.

De acordo com a combinação C de Tarapanoff (2001), exemplificada no Quadro 4, o ponto fraco 'baixo envolvimento participativo' deve ser corrigido, pois caso contrário, a associação não conseguirá aproveitar as oportunidades. Tendo em vista que os 'Projetos' tem como parâmetros avaliativos o nível de união e organização das instituições beneficiárias, comprovado a partir da frequência da realização das reuniões e da assiduidade participativa dos/as sócios/as.

Para alcançar alguns parâmetros de capacidade organizativa, pontua-se um comportamento essencial, a responsabilidade, que abre seu leque para os compromissos, analisados pelas indicações internas: 'participação nas reuniões, mutirões e coletivos' e 'contribuição/arrecadação ativa das mensalidades', observadas no Quadro 5.

QUADRO 5 - Avaliação de forças e fraquezas a partir do comportamento responsabilidade

1. Fatores Internos

\begin{tabular}{|c|c|c|c|}
\hline 1.1 Forças & $n_{i}$ & 1.2 Fraquezas & $n_{i}$ \\
\hline $\begin{array}{l}\text { Contribuição ativa, Doação, Apoio } \\
\text { financeiro, arrecadação das mensalidades } \\
\text { dos/as sócios/as }\end{array}$ & 7 & $\begin{array}{l}\text { Baixa participação nas reuniões, nos } \\
\text { mutirões/coletivos }\end{array}$ & 8 \\
\hline $\begin{array}{l}\text { Mão de obra, Mutirão/ trabalho coletivo } \\
\text { (ex.: nas moagens) }\end{array}$ & 6 & Poucos recursos financeiros & 5 \\
\hline
\end{tabular}

Fonte: Resultados da pesquisa (2019).

As contribuições mensais dos/as associados/as são usadas para suprir as despesas com manutenção do prédio da sede da associação, deslocamentos, declarações anuais feitas pelo/a contador $/ \mathrm{a}^{4}$, entre outros. A adimplência do apoio financeiro; alocada na matriz FOFA como uma indicação positiva do ambiente interno, mas com frequência mediana; é um fator necessário para a criação de um fundo reserva, pois os poucos recursos financeiros foram apontados como uma fraqueza para as associações, limitando-as na aquisição de bens e materiais, equipamentos e ferramentas, matérias primas e transporte. Segundo Tarapanoff (2001) se os recursos corretos não estiverem disponíveis, não é possível atingir a Tarefa 3, que tem o objetivo de minimizar, evitar ou eliminar os fatores negativos. Ou seja, converter as fraquezas em fortalezas.

A Associação B relembra que quando existia trabalho coletivo (indicação apontada por seis associações como força e por oito como fraqueza) na associação, no engenho com a produção de cachaça e no cultivo de uma área coletiva de dois hectares de cana-de-açúcar, maracujá, feijão e milho, a arrecadação era suficiente, até utilizavam-na para pagar as parcelas do Crédito Fundiário. Suas receitas são constituídas apenas com a mensalidade de $R \$ 3,00$, que não suprem as despesas da associação com documentação, contador, cartório, energia da sede,

\footnotetext{
${ }^{4}$ Ressalta-se que, as associações do município de Camocim, possuem isenção dos custos com contador/a, pois passou a ser responsabilidade da gestão pública.
} 
deslocamento e alimentação. Tentaram aumentar a contribuição para $R \$ 5,00$, mas os/as associados/as não concordaram. Segundo a Associação $A$, além da contribuição mensal, quando necessitam de uma benfeitoria, unem esforços financeiros, como por exemplo, o caso da cerâmica na sede, colocada a partir de doações dos/as associados/as e da reforma custeada pela arrecadação de leilão beneficente e promovido pela comunidade.

Das 15 associações, cinco ( $C, E, F, G$ e $L)$ não estão ativas em relação às contribuições mensais, três delas estão concentradas no Território 2 (Litoral Extremo Oeste). Alguns/mas associados/as apresentaram-se cansados/as e desestimulados/as com a falta de comprometimento. Entretanto, esse comportamento deficiente faz parte do passado de algumas associações, pois relembram do receio em deixar recurso na associação, evitando assim, a deslealdade da diretoria. Com o tempo, perceberam a importância de possuírem um fundo de reversa.

Ainda no Quadro 5, analisa-se a outra indicação que dialoga com o comportamento da responsabilidade: 'participação dos/as sócios/as nas reuniões, nos mutirões/coletivos'; apontada como a maior fraqueza para oito associações. As associações reconheceram que não estavam organizadas e fortalecidas para receber projetos e consequentemente "vingar", e reinteraram a importância da participação nas reuniões, ao dizerem que "as ações e as oportunidades chegaram através da participação nas reuniões" (informação verbal) ${ }^{5}$.

Envolvendo assim, a motivação e o ânimo para o desenvolvimento e conquistas coletivas das associações, é possível confirmar na Matriz FOFA tais indicações como fracas. A desmotivação e o desânimo nas organizações, juntamente com a instabilidade política das administrações locais, são alguns fatores internos que pode levar a ruptura e/ou descontinuidade de oportunidades como projetos/programas.

Com isso, analisa-se outro caso na Combinação C, no Quadro 6 abaixo, pois são fundamentais as parcerias e o apoio (apontadas como oportunidade na FOFA) às/aos produtoras/es na articulação de novas formas de relacionar com o governo e com a rede social de sujeitos que estimulam uma distribuição de produtos com valor mais favorável. Podem ser citadas parcerias e apoio como do Sindicato dos Trabalhadores Rurais, da Empresa de Assistência Técnica e Extensão Rural do Ceará (EMATERCE) e do Agropolos.

QUADRO 6 - Combinação alternativa de fator externo positivo (Oportunidade) com fator interno negativo (Fraqueza).

\begin{tabular}{|l|c|c|}
\hline Fator interno $\quad$ Fator externo & OPORTUNIDADE & AMEAÇA \\
\hline PONTO FORTE & (A) & (B) \\
\hline $\begin{array}{c}\text { PONTO FRACO } \\
\text { Desmotivação, desânimo }\end{array}$ & $\begin{array}{c}\text { (C) } \\
\text { Parcerias e apoio }\end{array}$ & (D) \\
\hline
\end{tabular}

Fonte: Resultados da pesquisa (2019).

Vale ressaltar ainda a 'terra' como uma indicação interna positiva, no sentido de posse e conquista. Para Martinez (2001) a falta de terra própria é uma dificuldade, pois na ausência de posse, os/as agricultores/as não se animam em

\footnotetext{
${ }^{5}$ Informação fornecida em outubro de 2017, durante o Módulo I, na Associação F, Camocim-CE. ENCICLOPÉDIA BIOSFERA, Centro Científico Conhecer - Jandaia-GO, v.17 n.31; p. 98 
investir em melhorias e não tem a segurança de pertencimento. As seis associações que apontaram essa fortaleza na Matriz FOFA são as representadas por $40 \%$ em Assentamentos Rurais, em que as Associações B, C, G e L competem ao Programa Nacional de Crédito Fundiário (PNCF) e as Associações $F$ e $\mathrm{H}$ ao Programa Nacional de Reforma Agrária (PNRA).

O texto de Marques (2008) sobre o campesinato no mundo e no Brasil, ajuda a entender que a idade do assentamento pode influenciar no seu nível de produção, visto que após a luta pela terra a criação da associação vem acompanhada por um conjunto de medidas que formalizam o reconhecimento do Estado de seu dever de assegurar o acesso a direitos básicos como educação, saúde, lazer, trabalho e habitação. No caso dessas associações, B, C, F, G, H e L, a média de idade de assentamento rural é de 20 anos.

Frente a esses progressos com a aquisição de terra para cultivar e criar, se faz importante desenhar e justificar o cenário de ameaças da FOFA, ao eleger os invernos irregulares como a principal dificuldade externa para o meio rural produzir e comercializar. Segundo Denhardt (2012), um dos elementos, necessários no planejamento, controle e direção da gestão econômica e financeira da propriedade rural, estendendo-se para as associações, são os eventos climáticos.

A elevação das temperaturas, a irregularidade das chuvas e a perda da fertilidade dos solos aumentam a escassez dos produtos e logo fragilizam a comercialização da agricultura familiar. Logo, conforme os/as agricultores/as das associações "A seca é a coisa que mais desmotiva o homem do campo, então a gente tem que aprender a conviver com ela" (informação verbal) ${ }^{6}$.

Precisamos aprender a viver com esse semiárido, pois a nossa terra aqui é riquíssima em qualquer tipo de plantação, a gente sente que tem progresso (...) A gente sabe que lugar seco é difícil de tirar a sobrevivência, tem que unir os conhecimentos, se atualizar. (informação verbal, grifos nossos) ${ }^{7}$.

Diante das falas, observou-se na FOFA que os 'invernos irregulares' foram a ameaça mais frequente para os/as associados/as comercializar, pois com a diminuição dos recursos pluviométricos, a produção reduziu, ficou limitada para o autoconsumo e sem excedente, fazendo com que as associações buscassem alternativas e estratégias para conviver com esse quadro de estiagem.

Os períodos de estiagem fazem parte da natureza, mas a escassez não pode significar prejuízos para os/as agricultores/as familiares. Por isso, o Governo do Ceará investe em novas tecnologias de convívio com o clima semiárido ${ }^{8}$; estas nomeadas na FOFA de 'recursos hídricos', como cisternas e poços profundos, são assinaladas por todas as associações como uma oportunidade (ver Quadro 2). Seguindo os esquemas de Tarapanoff (2001), para minimizar essa ameaça, combina-se com as oportunidades disponíveis.

Com toda a dificuldade hídrica, os/as associados/as compartilham em suas falas que o desenvolvimento da comunidade ou do assentamento se deu a partir das políticas públicas vinculadas ao Semiárido (indicação caracterizada na FOFA como

\footnotetext{
${ }^{6}$ Informação fornecida em dezembro de 2017, durante o Módulo I, na Associação L, Iguatu-CE.

${ }^{7}$ Informação fornecida em novembro de 2017, durante o Módulo I, na Associação H, Granja-CE.

${ }^{8}$ Segundo Ceará (2016), 86\% do território do estado do Ceará são caracterizados como semiárido, ou seja, tem um clima de poucas chuvas e muita seca. Apenas o litoral e alguns pontos isolados no interior do estado - como Serra da Ibiapaba - têm o clima menos seco.
} 
oportunidade). Entre as mais citadas estratégias do governo, destacam-se as cisternas do Programa Uma Terra e Duas Águas $(P 1+2)$. São reservatórios de 16.000 litros que captam e armazenam água da chuva para auxiliar na produção de alimentos, tanto vegetal como animal. A água captada é utilizada na irrigação dos quintais produtivos, para cultivar fruteiras, hortaliças e plantas medicinais, bem como para a criação de animais ${ }^{9}$.

A limitação é o número de cisternas distribuídas por família e a diversificação destas. No Gráfico 1 tem-se a quantidade de famílias das associações pesquisadas, em percentual, que acessam o $\mathrm{P} 1+2$, de acordo com o levantamento inicial (Marco $0)$ e com após um ano (Marco 1) de acompanhamento técnico realizado pelo Instituto Agropolos. Percebe-se que os Territórios 1 e 2, que correspondem a Serra da lbiapaba e o Litoral Extrema Oeste, tem os mais baixos índices. As Associações G e F, por exemplo, do Território 2, não foram ainda beneficiadas com as cisternas de placa. $E$ as Associações $A, B$ e $E$, que no marco 0 não possuíam, foram recebendo ao longo da ATER.

Dentre as soluções apontadas como plano de ação, para minimizar essa ameaça, têm-se como principais: aprender a conviver com a seca, fazendo manejos e solicitando projetos de abastecimento de água, como a construção de mais cisternas de placa e de cisterna-calçadão, perfuração de poços profundos, e utilização de métodos de irrigação para o plantio que consomem menos energia, ou seja, com contador tarifa-verde para minimizar as taxas de energia.

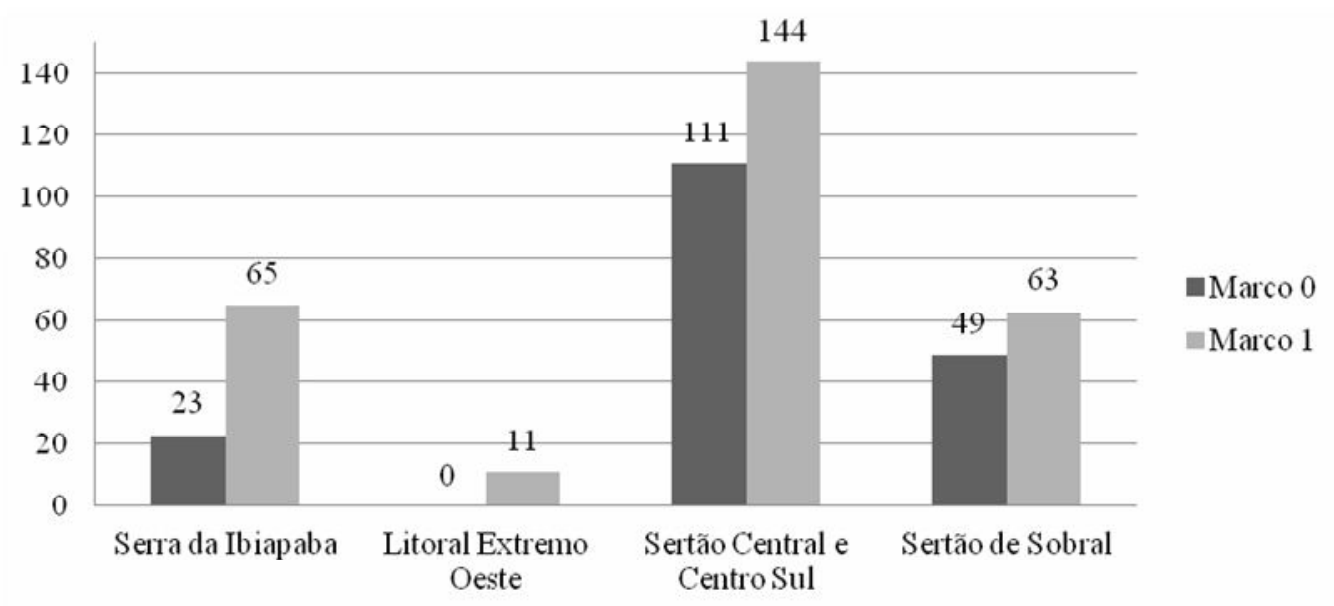

GRÁFICO 1 - Levantamento de famílias beneficiadas com cisternas de placa (AGROPOLOS, 2018).

Essas adversidades no fator climático podem ser agravadas com o aumento de 'queimadas e desmatamento' e do 'uso de agrotóxico', que são indicações assinaladas em ameaças (ver FOFA no Quadro 2). De acordo com o perfil tecnológico com sustentabilidade revelado no relatório do Agropolos, a chegada da ATER conscientizou as associações a reduzir o nível de queimadas e o uso de agrotóxico. O despertar da consciência, segundo os/as associados/as, é influenciado pela existência de experiências bem-sucedidas voltadas para a promoção da agroecologia. Após a vivência em intercâmbios, muitos/as agricultores/as estão

\footnotetext{
${ }^{9}$ São assinaladas na Matriz FOFA como fortalezas dentro da associação a 'produção diversificada'; a 'criação de animais', reforçando as atividades na apicultura, ovinocaprinocultura e avicultura; e o 'quintal produtivo'; entretanto, não apareceram com frequência relevante para exibir no Quadro 2.
} 
aptos às mudanças de comportamentos e se disponibilizam e se interessam em recuperar e ressignificar os sistemas produtivos a partir da adoção de práticas agroecológicas nas suas unidades familiares, repercutindo na conservação dos recursos naturais e das biodiversidades. Afinal, de acordo com o associado da Associação L, “(...) não existe terra ruim, existe manejo inadequado"10.

Deste modo, a busca pela sustentabilidade fundamenta-se na capacidade de inovação dos/as agricultores/as familiares, melhorando o desempenho da economia, ampliando a geração e agregação de valor a partir da comercialização dos produtos, e reduzindo custos de transação, uma vez que diminui e/ou elimina a dependência de insumo externo no controle de pragas e doenças nas unidades produtivas (ameaça da matriz FOFA); suficiente para gerar mais bem estar social e ambiental.

\section{CONCLUSÕES}

As fortalezas, fraquezas, oportunidades e ameaças das associações pesquisadas demonstra que o componente organizativo desempenha um papel importante no acesso à comercialização, ao minimizar os riscos de se tornarem passivas e dependentes de agentes externos e ao maximizar os benefícios de investimento que políticas e/ou projetos trazem, expressando os fatores internos e externos para tratar com eficiência as incertezas, aproveitando bem as oportunidades e reduzindo os eventos negativos.

Foi possível entender algumas dificuldades existentes entre os fatores analisados nas organizações sociais, tais como deficiência do desenvolvimento vivencial do grupo, precária condição de execução das tarefas grupais, gestão desmotivada e exclusão ou desvalorização de oportunidades de apoio de agentes externos para alcançar seu desenvolvimento socioeconômico. Assim como, foi observado que as associações que atuam com capacidade de articulação e de relacionamentos, capazes de gerar um ambiente de cooperação, participação, confiança e flexibilidade, estão mais bem preparadas para assegurar um desempenho mais eficiente no desempenho da comercialização.

Revelou-se que os fatores positivos influenciam para que os grupos se consolidem e vençam suas limitações e condições externas negativas que as impedem de dar um salto qualiquantitativo. Esta transição requer uma gestão horizontal, que haja interação entre as partes interessadas; suas estratégias devem estar compartilhadas tornando transparente o cenário do ambiente e; a tomada de decisão da associação deve ser coletiva. Além disso, vale ressaltar que as organizações sociais precisam se comportar de forma profissional, para que neste contexto de globalização, possam estar preparados para enfrentar tanto os atuais desafios, que serão gradativamente superados, quanto os novos, evitando assim um retorno ao padrão social e econômico de necessidade básica extrema.

\section{REFERÊNCIAS}

AGROPOLOS. Instituto Agropolos do Ceará. Notícias. IDESQ e PSJIII apresentam metodologias de trabalho para coordenadores do IACe. Set. 2017. Disponível em: http://www.institutoagropolos.org.br/noticia/2664.

BELIK, W.; CUNHA, A.R.A.A. Abastecimento no Brasil: o desafio de alimentar as cidades e promover o desenvolvimento rural. In: GRISA, C.; SCHNEIDER, S.

\footnotetext{
${ }^{10}$ Informação fornecida em dezembro de 2017, durante o Módulo I, na Associação L, Iguatu-CE.
} ENCICLOPÉDIA BIOSFERA, Centro Científico Conhecer - Jandaia-GO, v.17 n.31; p. 101 
Políticas Públicas de desenvolvimento rural no Brasil. Porto Alegre: UFRGS Editora, 2015. p. 217-235.

CARDOSO, U.C. Associação. Brasília: Sebrae, 2014. 46p. : il. (Série Empreendimentos Coletivos).

CASTRO, I.M.N.; JAMEL, C.E.G. Marco de Gestão Socioambiental - MGSA. Projeto de Desenvolvimento Rural Sustentável do Estado do Ceará - Projeto São José IV, 2019.

CEARÁ. Secretaria de Desenvolvimento Agrário. SDA. Revista do Projeto São José III, Ceará, ano 1, n. 3, 27p., jul. 2016.

CEARÁ. Secretaria de Desenvolvimento Agrário. SDA. Manual de operações do Projeto (MOP). Projeto de Desenvolvimento Rural Sustentável (PDRS) /Projeto São José III. Fortaleza: SDA, 2019.

DENHARDT, R.B. Teorias da Administração Pública. São Paulo: Ed Cengage Learning, 2012.

FAGOTTI, L.N. Associativismo e agricultura familiar: reflexões sobre uma associação de produtores rurais no interior paulista. REDD - Revista Espaço de Diálogo e Desconexão, Araraquara, v.9, n.1 e 2. 2017. DOI: https://doi.org/10.32760/19841736/REDD/2017.v9i1.1094. Acesso: 13 fev. 2018.

HINDLE, T.; LAWRENCE, M. Field Guide to Strategy: A Glossary of Essencial Tools and Concepts of Today Managers. Harvard Business School Press, 1994.

MARQUES, M.I.M. Agricultura e campesinato no mundo e no Brasil: um renovado desafio à reflexão teórica. In: PAULINO, E.T.; FABRINI, J.E. (Org.). Campesinato e territórios em disputa. 1. ed. São Paulo: Editora Expressão Popular, 2008, p. 4978.

NOFFKE, S.; SOMEKH, B. Pesquisa de ação. In: SOMEKH, B.; LEWIN, C. (Orgs.). Teoria e métodos de pesquisa social. Petrópolis, RJ: Vozes, 2015. p. 141-149.

ROCHA, F.E.C. Agricultura familiar: dinâmica de grupo aplicado às organizações de produtores rurais. Planaltina, DF: Embrapa Cerrados, 2004.

SCHNEIDER, S. Mercados e Agricultura Familiar. In: MARQUES, F.C.; CONTERATO, M.A.; SCHNEIDER, S. (Orgs.). Construção de mercados e agricultura familiar: desafios para o desenvolvimento rural. Porto Alegre: UFRGS Editora, 2016. p. 93-140.

SENAR. Serviço Nacional de Aprendizagem Rural. Associações rurais: práticas associativas, características e formalização. Brasília: SENAR, 2011.

TARAPANOFF, K. (Org). Inteligência Organizacional e Competitiva. Brasília: Editora UNB, 2001.

YIN, R.K. Estudo de caso: planejamento e métodos. 5. ed. Porto Alegre: Bookman, 2015. 